\title{
The Strategy of Management Training in the Construction Engineering
}

\author{
Elena Khripko $^{1, *}$ \\ ${ }^{1}$ Moscow State University of Civil Engineering, Yaroslavskoe shosse, 26, Moscow, 129337, Russia
}

\begin{abstract}
The operating efficiency of leaders in the construction industry is largely determined by the level of formation of managerial skills. Along with this, it is stated that the process of formation and development of managerial skills for leaders in the construction engineering is attended by a number of difficulties and frequently doesn't make it past the threshold. This paper formulates a new approach in the formation of managerial skills of leaders in the construction engineering. The cross-sectoral assessment of managerial skills featuring the heads of the construction engineering and other industries, such as energy, metallurgy, showed low-performing managerial skills for the heads of the construction industry. The reasons of the formation of low-performing managerial skills in this article are referred to as peculiar features of organizational behavior in the construction engineering, in particular an imminent regression in the leader-follower system. Based on the results of the research conducted, the similarity of issues in regard to managerial skills in these areas is inherent in key differences in the formulation of priorities of corporate competencies.
\end{abstract}

\section{Introduction}

Construction engineering is a technologically complex business that determines high-level requirements to the development of managerial skills for leaders [1]. It must be noted that the issue of implementing the managerial function is still important [2]. The relevance of this topic is supported by requests of chief executives and human resources department for the purpose of finding ways to improve the managerial skills [3]. Too much attention is paid to the issues of formation of managerial skills in the system of professionally-oriented higher education $[4,5,6]$. The search of best practices for personnel management to develop and improve managerial skills for leaders encounters the selection problem, determining criteria of best practices and tools to develop leaders in the industry.

In order to define strategies to improve the level of managerial skills, it seems practical to compare the evaluation findings of its development level for leaders in the construction engineering and for leaders in other industries [7,8]. The working hypothesis in preparation of this study was based on the analysis of competency profiles for the participating

\footnotetext{
* Corresponding author: geleda@ya.ru
} 
companies submitted for approval, and the analysis of heads personnel estimation. It was expected that the development level of managerial skills for "builders" will be identical or even higher in comparison with the heads of other branches.

The tools for personnel estimation by competencies are widely used in the human resource management practice [9]. In this study, the psychoanalytic approach was applied for the development of assessment tools $[10,11]$. Using the psychoanalytic approach while developing content and interpretation of the given results essentially supplements and clarifies the information about the level of forming competences, as well as offers an opportunity to reveal the causes of resistance that complicate a stable demonstration of competencies in organizational behavior and blocking its demonstration [12]. The results of measuring competencies without using the psychoanalytic approach inform the conscious level of organizational behavior, while hidden and destructive tendencies stay out of the field of research and change.

The reason of "blind spots" in the competency measurement is that the evaluation items, peculiarly the description of competencies and indicators of its demonstration, focused on the identification of the ability to evaluate the organizational behavior of employees that corresponds to the successful activity in the given area.

In practice, HR coordinators often encounter the difficulty that the evaluation findings can differ from the actual manifestation of the development level of competencies in organizational behavior. This happens due to the actualization of different types of hidden and unreflected tendencies that are difficult to reveal throughout the evaluation process.

If you go with the approach to measure competencies from the perspective of the quality of object relations for estimated employees, it becomes possible to study patterns of organizational behavior that determine the implementation of competences in everyday commercial practice. Object relations, structuring organizational behavior and defining the implementation of competencies, are in focus of the study of modern applied psychoanalysis. Applied psychoanalytic studies have proven its effectiveness in the study of the processes taking place in organizational environments. The concept of object relations applied to the study of the organizational environment should be considered as follows. This is the result of a perceptual unit of one individual by another, which determines the level and character of personality development in general and underlying patterns of person-to-person interaction in the organizational environment. Carriers of a certain quality of object relations transmit them to the organizational environment, defining the level of organizational interaction, so by object relations we also mean the nature of interaction between employees. To complete understanding of what is meant by object relations in organizational behavior, it is necessary to admit an assumption that the psychical reality of participants in organization is structured by internal objects. Internal objects from the psychoanalytic point of view are external internalized objects, as well as elements of their operation, considered from the perspective of individual experience.

The individuals that create an organizational environment adapt their ontogenetic experience to it, as a result the nature of organizational interactions gets a certain quality. In relation to the individual, the quality of object relations realized in organizational behavior will have a regressive status. This is one of those factors that determine the difference between the manifestation of employee competencies in real activity as compared to this one that demonstrates in the course of the evaluation procedures.

\section{Experimental section}

The selection of key managerial skills was performed by customers of personnel estimation (company executives and leaders of the first-line management) using the focus group 
method where moderators were external consultants. For a comparative analysis, certain competencies and similar profiles of managerial positions were chosen according to the description. The evaluation procedure of executives was carried out by using two tools: assessment center and 360-degree assessment.

The results were compared for all types of correspondence: competency profile (by the composition defined for the evaluation by the results of focus groups), profiles and assessment tools. The results of focus groups to evaluate company executives were identified the following competencies: management and organization, strategic thinking, planning, influence, decision making. It was also determined the following content of competencies.

1. Management and organization. The leader clearly and specifically set goals to his subordinates and colleagues, and achieving goals occurs through the efficient workflow management,takes the responsibilityfor the tasks accepted by subordinates, creates conditions to develop the professional level forhis employees, provides a clear and detailed feedback, helps overcome difficulties in acquiring expertise, builds the interaction between employees tosynchronize their activities, gives a realistic assessment of attained results.

2. Strategic thinking. The leader shows a broad view on prospects of the organization, puts ambitious aims, forecasts the sequence of events, plans his activities and activities of his subordinates systematically based on the prospects of organizational development, tendencies and limitations, in the decision-making process he involves his subordinates and colleagues, implementsthe system of preventative activities, effectively reduces the likelihood of resistance on the way toward the target.

3. Planning. The leader plans the workflow in accordance with current and long-term goals of the organization based on the selected goals and objectives, and offers a variety of scenarios, develops planning skills of his employees.

4. Influence. The leader effectively brings influence to bear, convinces or affects others in order to achieve agreement or behavioral change, defends his opinion over most or opponents having a higher status, he is able to persuade his opponent to change his position without entering into the conflict and saving a friendly business relationship with him.

5. Decisionmaking. The leader quickly makes decisions andproceeds to actions,by making decisions, he takes into account their impact and consequences to other activities of units and organizations as a whole, helps subordinates develop the ability to make decisions within the framework of their powers.

It should be noted that the coincidence of evaluation items ofmanagerial skills, the selection of corporate competencies revealed distinct differences of leaders' opinions in the construction industry and in other branches. Non-construction companies demonstrated a general tendency in the selection of corporate competencies. The most popular among them were:

1. Customer-oriented approach. The leader is focused on internal and external customer, distinguisheshis needs and strives to maximize the satisfaction of these needs while respecting the interests of the organization.

2. Communication. The leader is able to establish and maintain partnership relations with colleagues, as well as clearly delivers the information, effectively interacts with colleagues and subordinates choosing thecommunication style which corresponds to the situation and type of an opponent, builds arguments based on facts and evidenceswith account of partner's interests.

3. Corporational nature. The leader knows and accepts corporate policies, norms and values acting on behalf of the organization's interests, he is a supporter and a carrier of corporate culture, knows the standards and values of the organization, applies them to 
work, transfers his knowledge and experience to colleagues, promotes the formation and maintenance of a positive image of the organization.

4. Self-development. The leader consciously strives to get new knowledge, skills and experience, interested in the use of new opportunities in professional activities, believes that the development is one of the basic conditions for competitiveness and success, takes participation in training events to improve his professionalism, takes the part in the community of professionals, shares new information with others, seeks to involve them into the development process.

5. Flexibility. The leader effectively acts under the conditions of changes, successfully adapts to new challenges, successfully adapts and makes the right decisions in unusual situations, in the event of difficulties quickly changes the behavior plan according to the situation, offers non-standard and new solutions to common issues and problems using the situation of uncertainty to increase the effectiveness of the organization.

The selection of chief executives for construction companies revealed that the following corporate competencies are the most popular:

1. Responsibility. The leader is ready to be in charge of results and consequences of his actions, of working results beyond its own area of responsibility. In case of failure, he takes responsibility and the most part of activities to normalize the situation.

2. Analytical skills. The leader is oriented at the information flow, differentiates information and draws conclusions based on it taking into account the various factors affecting the efficiency.

3. Emotional resilience. The leader controls his emotional state in the changing situation and in the situation of uncertainty, constructively resolves outstanding issues, successfully resolves disputed situations, depending on the complexity of the situation he doesn't show his emotional state. Under pressure, his effectiveness is decreased and he is able to continue to achieve the result.

4. Result-oriented performance. The leader tends to satisfy the objectives efficiently and on time, bring the final result to a qualitatively higher level. The results of his work exceed expectations and he helps other employees in the task performance.

The presentation of the evaluation findings and the feedback from company executivies and assessment participants is conducted in the format of coaching sessions. The material analysis of the whole complex by managerial activity appraisal makes it possible to answer all questions posed in the study to determine the development strategy of the personnel: a new direction of improving managerial skills for leaders in construction engineering. The couch session reveals managerial skills in need of development according to leaders. The selection of corporate competencies indirectly points to the problems of the organizational environment in the organization.

\section{Results}

622 chief executives of 654 selected took participation in this study to evaluate managerial skills, while $313(50.3 \%)$ are leaders of construction companies, and $309(49.7 \%)$ - leaders from other industries (mainly metallurgy and energy). The assessment participants amounted to $95 \%$ of the total number of managers, adequately, of the second and third levels of management. The comparative analysis of managerial skills for leaders of the second and third levels of management showed that the evaluation findings of leaders of non-construction industries are coincident with the spread of the values of $1 \%$, and the evaluation findings of leaders in construction engineering were on average lower by $16.8 \%$. Moreover, low-performing managerial skills have been identified both in the case of the evaluation center andon application of the 360 degree evaluation with almost the same 
difference with respect to the evaluation findings of leaders of other branches: the Evaluation center- $16.6 \%$, the 360 degree evaluation - $17 \%$.

\section{Discussion}

First of all, conspicuous is the fact that that the selection of corporate competencies is radically different from competencies for leaders in construction engineering. The need to increase the responsibility level, analytical skills, stress resistance and focus on achieving results characterizes a corporate mainstream in general. And it is - from a psychoanalytic point of view - a high level of anxiety blocking the ability to analysis and non-reflexive avoidance of responsibility. Similar manifestations become actual due to the fact that the psychological regulator of managerial function performs a stereotypical "finger-pointing" that causes the deformation in the implementation of managerial skills. Thus, the boost of managerial skills in this case should be seen in the system: management - organizational behavior. I note that the preliminary interpretation of organizational issues on the basis of the selection of corporate competencies was confirmed in a further study of the patterns in organizational behavior of construction companies that participated in the heads personnel estimation. The organizational environment of construction companies has specific features identified with the request for the assessment and the further development of corporate competencies.

Low-performing managerial skills are largely due to the fact that the professional competencies in the construction engineering are characterized by complexity, high capacity and duration of development up to the experience level. A great impact affected by the fact that the duration of development in the building sector and vital cycle of these construction sites substantially is increased in comparison with the fact that happens in other business activities. The relative decrease of low-performing managerial skills in construction engineering is confirmed by the fact that the development plan of managerial skills in construction companies that is common in business doesn't give the expected result. In most cases, company executives come to the conclusion that the leaders are applied high requirements in a purely professional sphere, therefore, the simultaneous highlevel combination of professional and managerial skills is unlikely. These conclusions of such efforts and resources are usually directed at the improvement of recruitment.

The notion that the leaders in the construction industry are applied strict requirements in comparison with the leaders from other industries, it is impossible not to agree. However, I believe that the reason of low-performing managerial skills is rooted in the specifics of the system: organizational structure - corporate culture - company management in the building industry. Let's consider theorg-structural aspect. The construction activity has more design characteristics as compared with other activities. However, the research of organizational patterns for construction companies, the evaluation findings of that are discussed in this article, doesn't sufficiently correspond to the design characteristics. As a rule, the project activities are made in the form of authority line and staff in different variations. Therefore, the lack of organizational structuring will inevitably be compensated by the dynamic aspect, i.e, the implementation of management function.

It should seem that this situation should facilitate the recruitment and promotion of leaders with the excellence of managerial skills. In practice, based on the evaluation, we consider the opposite tendencies. In preceding proceduresI described the organizational environment as a system of object relations that have different qualities depending on the level and characteristics of organizational behavior. The psychoanalytic study of the quality evaluation of object relations in the corporate participantsin the follower-leader system has shown that in the construction companies they have more regressive character. The lack of 
organizational structuring and the amount of professional and managerial requirementshas an effect on the quality of object relations in the follower-leader system. The follower-leader system is inevitably exposed tothe defensive regression of object relations of its constitutives. The regressive quality of object relations accumulates anxiety and guilt that, in turn,demonstrates as a necessity to develop corporate responsibility, emotional resilience, analytical skillsand demand of greater impact. The immanent regression provides an adaptive decrease of managerial skills. In virtue of this specific adaptive behavior, the program outputs of managerial skills are broken down and don't havethedesired effect. Therefore, the strategy of improving managerial skills should be built not in the usual logic of a direct impact on them, but in terms of object relations from a regressive state.

Back to the relative decrease in managerial skills in construction companies. The analysis of coaching sessions showed that leading positions take those leaders who are able to adapt to the regressive level of object relations. In turn, the regressive state of the follower-leader-organizational environment systempromotes low-performing managerial skills, but,at the same time, provides the state of relative organizational stability. The regressivelevel spreads in the organization environment through indicating, unconscious identification with the "successful model".

Obviously, the priority activity to improve the situation should be a diagnosis of indicating sources and organizational broadcast of regressive patterns in organizational behavior. After that it's necessary to develop the plan for the corporate culture that would help reduce the protective regression and would direct atthe quality improvement of object relations for leaders along with traditional programs of managerial skills.

\section{Conclusions}

The conducted research is a comparative judgement of heads personnel in construction and non-construction industries, and interpretation of research results with the psychoanalytic approach that allows making a number of preliminary conclusions:

1. The cross-sectoral personnel estimation makes it possible to get additional information about the development level of managerial skills for leaders in thein the construction engineering.

2. The results, obtained by evaluating 622 chief executives, half of them work in the construction engineering, show low-performing managerial skills for leaders in the construction engineering. The obtained data need to be tested for the enhanced research base that will make it possible to confirm the hypothesis about the relative decrease of managerial skills in the construction industry or to give momentum to the further search of development strategies in personnel management.

3. Low-performing managerial skills in construction companies areexplained by a regressive state of the leader-follower system in organizational environment. This regression is adaptive and protective in nature that provides the stability of organizational behavior in general.

4. Activities, aimed at the conclusion of object relations from a regressive state, enhance the level of managerial skills directly showed in organizational behavior. The development strategy of managerial skills can be defined as a goal-oriented activity to improve the quality of object relations in the leader-follower system in organizational environment. 


\section{References}

1. A.S. Hanna, M.W. Ibrahim, W. Lotfallah, et al, Journal of Construction Engineering and Management, 142(8), 4016029 (2016)

2. K. Gerasimov, B. Gerasimov, Int. J. of Educational Management, 31, 1 (2017)

3. E. V. Romanova, SGEM-2016, Finance. Economic and tourism (2016)

4. N. G. Miloradova, A. D. Ishkov, Advanced Materials Research, 1065-1069, 2538$2541(2015)$

5. A. D. Ishkov, M.G. Leontev, Procedia Engineering, 117, 142 -147 (2015)

6. E.A.Shnyrenkov, I.P. Pryadko, Procedia Engineering, 117, 325-330 (2015)

7. N. G. Miloradova, A. D. Ishkov, MATEC , 73, 07003 (2016)

8. P. Lekshmi, R. Radhika, Journal of Chemical and Pharmaceutical Sciences 9, 4 (2016)

9. M. Bohlouli, N. Mittas, G. Kakarontzas, et al., A mathematical approach Expert Systems with Applications, 70, 15 (2017)

10. E. Khripko, MATEC , 73, 07021 (2016)

11. A.D. Sant'Anna, International Forum of Psychoanalysis, 21, 1 (2012)

12. O.F. Kernberg, R. Michels, Journal of the American Psychoanalytic Association, 64, $3,(2016)$ 